Article

\title{
Reusability of Immobilized Cells for Subsequent Balsamic-Styled Vinegar Fermentations
}

\author{
Ucrecia F. Hutchinson ${ }^{1,2, *}$, Seteno K. O. Ntwampe ${ }^{2,3}$, Boredi S. Chidi ${ }^{1,2}{ }^{(1)}$ \\ Maxwell Mewa-Ngongang ${ }^{2}{ }^{(0}$, Heinrich W. du Plessis ${ }^{1}$ (D), Mardé Booyse ${ }^{4}$ and Neil P. Jolly ${ }^{1, *}$ \\ 1 Post-Harvest and Agro-Processing Technologies, ARC Infruitec-Nietvoorbij (The Fruit, Vine and Wine \\ Institute of the Agricultural Research Council), Private Bag X5026, Stellenbosch 7599, South Africa; \\ boredi2002@gmail.com (B.S.C.); dplessishe@arc.agric.za (H.W.d.P.) \\ 2 Bioresource Engineering Research Group (BioERG), Faculty of Applied Sciences, \\ Cape Peninsula University of Technology, P.O. Box 652, Cape Town 8000, South Africa; \\ Karabo.Ntwampe@nwu.ac.za (S.K.O.N.); mewamaxwell@gmail.com (M.M.-N.) \\ 3 School of Chemical and Minerals Engineering, North-West University, Private Bag X1290, \\ Potchefstroom 2520, South Africa \\ 4 Agricultural Research Council Biometry, Private Bag X5026, Stellenbosch 7599, South Africa; \\ booysem@arc.agric.za \\ * $\quad$ Correspondence: Ucrecia@gmail.com (U.F.H.); Jollyn@arc.agric.za (N.P.J.); Tel.: +27-21-809-3174 (U.F.H.); \\ +27-21-809-3060 (N.P.J.)
}

Received: 3 August 2020; Accepted: 12 October 2020; Published: 29 October 2020

check for updates

\begin{abstract}
Cell immobilization is a process augmentation technique aimed at improving microbial survival and activity under stressful conditions. It offers the opportunity to reuse the immobilized cells for several fermentation cycles. The present study investigated the use of recycled cells entrapped in calcium-alginate beads and cells adsorbed on corncobs (CC) and oakwood chips (OWC) in subsequent fermentation cycles for balsamic-styled vinegar (BSV) production. Sugars, $\mathrm{pH}$, alcohol and total acidity were monitored during fermentation. Microbial activity and product formation declined when immobilized cells were reused for the second cycle for CC and OWC fermentations. Recycled cells entrapped in Ca-alginate beads completed the second cycle of fermentations, albeit at reduced acetification rates compared to the first cycle. Scanning electron microscope (SEM) imaging results further showed a substantial the structural integrity loss for Ca-alginate beads after the first cycle, and with minor changes in the structural integrity of CC. The OWC displayed a similar morphological structure before and after the first cycle. The sensory results showed that BSV produced using immobilized cells with Ca-alginate beads and CC was palatable, while those produced using OWC had negative attributes. Ca-alginate beads offered better protection for the fermentation consortium for culture reusability in BSV fermentations.
\end{abstract}

Keywords: balsamic-styled vinegar; Ca-alginate beads; cell immobilization; corncobs; oakwood chips

\section{Introduction}

Balsamic-styled vinegar (BSV), the focus of this study, is a derivative of traditional balsamic vinegar (TBV). The production of TBV follows strict regulations and generally employs conventional methods, which lead to longer fermentations in contrast to submerged methods used for BSV production [1,2]. The production of generic balsamic vinegar such as BSV does not have to adhere to such strict production regulations as TBV and their production using conventional methods is impractical for large-scale industrial production. Therefore, BSV can be successfully produced using techniques in which process performance augmentation strategies such as cell immobilization are applied $[3,4]$. Moreover, as TBV's are premium quality and high-priced products that most consumers cannot 
afford [1,2], other types of balsamic vinegars (i.e., BSV) can be an alternative. Therefore, BSV's should be produced to supply to a targeted consumer base. It is crucial to investigate methods to improve the quality of BSV by optimizing the fermentation process for cost-effective industrial-scale operations.

Previously, the effects of cell immobilization using Ca-alginate beads, corncobs (CC) and oakwood chips (OWC) on BSV production were studied [3,4]. However, the reusability of the immobilized cells was not evaluated. Optimal process performance and intensification at low-input cost are fundamental to the commercialization of BSV. Therefore, if recycled immobilized cells can retain a high microbial activity and at the same time retain high product formation rates, this can reduce overall input costs with substantial monetary savings in large-scale operations. Furthermore, the reusability and the performance of immobilized cells could probably vary, depending on the immobilization matrix or the technique that is used to immobilize the cells.

Corncobs are an agricultural by-product obtained from the corn milling process, with $80 \%$ of their dry matter being composed of cellulose and hemicellulose [5-7], while OWC are commonly used for flavor improvement in the wine industry to impart woody attributes to wine [8,9]. Polymetric matrices such as $\mathrm{Ca}$ - and Na-alginates are made from brown algae extracts and are known for their solidifying, gelling and stabilizing properties with diverse applications in the food and beverage industries [10].

For high cell retention and fermenter performance, cell immobilization has been frequently reported to have several advantages, with the option of reusing/recycling the immobilized cells being the prominent advantage [11-16]. However, limited studies on vinegar fermentation systems have been done to support the reusability of immobilized cells. Furthermore, most studies reporting on the recyclability of immobilized cells are based on monocultural one-step fermentation systems, whereby one species converts a single substrate directly into the final product [11,13-16]. However, for a BSV fermentation, a two-step consortia-driven process ensues, whereby sugar serves as the initial substrate for non-Saccharomyces yeasts, producing an intermediate product, i.e., alcohol, while the alcohol serves as a substrate for the subsequent production of acetic acid by acetic acid bacteria (AAB). This means that both the non-Saccharomyces yeast and AAB immobilized cells must survive the initial fermentation cycle, thus retaining adequate activity to be reused in successive fermentations. For this specific reason, this study investigated the reusability of a consortium of immobilized non-Saccharomyces yeasts and AAB previously used for BSV production [3,4]. Generally, the matrices used for cell immobilization are not only different with regard to their physical characteristics and origin but could also affect the sensorial attributes of the final BSV. As such, investigating the organoleptic properties of the final product, i.e., BSV, was also deemed necessary.

\section{Materials and Methods}

\subsection{Preparation of Fermentation Medium, Inoculums and Calcium Alginate Solutions}

The preparation of the fermentation medium (cooked grape must) was performed following the methodology described by Hutchinson et al. [3,4], with a working volume of $350 \mathrm{~mL}$ used for this study. Furthermore, the composition of the microbial consortium used, the preparation of pre-cultures and the preparation of calcium alginate-infused yeast extract-peptone-dextrose (YPD) medium and grape must (GM) solutions are described in Hutchinson et al. [3,4].

\subsection{Cell Immobilization: Gel Entrapment and Cell Adsorption}

The cell entrapment technique was conducted using a modified method adapted from Hutchinson et al. [3]. Yeast and acetic acid bacteria (AAB) cells were harvested by centrifugation (18 144 $\times g$ RCF, $5 \mathrm{~min}$ ) and transferred into YPD-alginate and GM-alginate solutions ( $3 \% w / v$ Ca-alginate) $(250 \mathrm{~mL})$ respectively, prior to mixing. The YPD and GM alginate solutions infused with cells were mixed to form a homogenous suspension. Subsequently, the Ca-alginate beads were formed by extruding the alginate solution infused with cells through a syringe into a $0.9 \%(w / v)$ sodium chloride $(\mathrm{NaCl})$ (Biolab, Merck, Modderfontein, South Africa) solution. 
Each bead $(4.5 \mathrm{~mm})$ contained both yeast and $\mathrm{AAB}$ cells, in contrast to the original method described in Hutchinson et al. [3], whereby yeast and $A A B$ cells were entrapped in separate Ca-alginate beads. The Ca-alginate beads were allowed to solidify for $1 \mathrm{~h}$ in the $\mathrm{NaCl}$ solution, as described by Kocher et al. [12]. Furthermore, cutting (CC only) and sterilization of CC and OWC were conducted using the method described by Hutchinson et al. [4]. However, due to working volume modifications, $C C$ were cut into a length of $3 \mathrm{~cm}$ each (Table 1). Furthermore, yeasts and AAB inoculums were mixed ( $200 \mathrm{~mL}$ per inoculum, i.e., $200 \mathrm{~mL} \times 10=2 \mathrm{~L}$ ) and the adsorbents (CC and OWC) were separately submerged into $1 \mathrm{~L}$ consortium mixture of yeast and $\mathrm{AAB}$ cells. The microbial consortium was allowed to adsorb onto the surface of the adsorbent overnight at $28^{\circ} \mathrm{C}$.

Table 1. Quantity of matrices used per $350 \mathrm{~mL}$ of fermentation medium.

\begin{tabular}{|c|c|c|c|c|c|}
\hline \multicolumn{6}{|c|}{ Adsorption } \\
\hline Adsorbents & $\begin{array}{l}\text { Length } \\
\text { (cm) }\end{array}$ & $\begin{array}{l}\text { Width/Diameter } \\
\text { (cm) }\end{array}$ & $\begin{array}{l}\text { Circumference } \\
(\mathrm{cm})\end{array}$ & $\begin{array}{l}\text { Surface Area of } \\
\text { One Piece }\left(\mathrm{cm}^{2}\right)\end{array}$ & $\begin{array}{c}\text { Total Adsorbent } \\
\text { Surface Area }\left(\mathrm{cm}^{2}\right)\end{array}$ \\
\hline Corncobs & 3.0 & 3.9 & 12.25 & 54.29 & 108.58 ( 2 pieces) \\
\hline $\begin{array}{l}\text { Oakwood } \\
\text { chips }\end{array}$ & 2.90 & 1.80 & 9.60 & 19.64 & 117 (6 chips) \\
\hline \multicolumn{6}{|c|}{ Entrapment } \\
\hline \multirow{2}{*}{$\begin{array}{l}\text { Ca-alginate } \\
\text { beads }\end{array}$} & \multicolumn{3}{|c|}{ Volume of Alginate Infused with Cells (mL) } & \multicolumn{2}{|c|}{ Diameter of Beads (mm) } \\
\hline & \multicolumn{3}{|c|}{20} & \multicolumn{2}{|c|}{4.5} \\
\hline
\end{tabular}

\subsection{Inoculation Procedure for First Cycle Fermentations}

The inoculation process for the Ca-alginate beads was similar to that previously described by Hutchinson et al. [3]. The same inoculation protocol of CC and OWC was followed as described by Hutchinson et al. [4]. However, since the working volume was decreased compared to the previous work done on adsorbed cell fermentations [4], the quantity of adsorbents used to inoculate the fermentations was reduced - see Table 1, which lists details of the quantity of matrices used per $350 \mathrm{~mL}$ of the fermentation media.

\subsection{Second Cycle Fermentation Experiments: Recovery and Reuse of Immobilization matrices}

After the completion of the first fermentation cycle, Ca-alginate beads were removed from the fermentation flasks using a sterile strainer and rinsed with sterile distilled water. Subsequently, the Ca-alginate beads were inoculated into $3 \times 350 \mathrm{~mL}$ cooked GM $\left(30^{\circ}\right.$ Brix $)$ and incubated at $28^{\circ} \mathrm{C}$ for the duration of the second cycle of fermentations. Similarly, CC and OWC were removed from the fermentation flasks using a sterile strainer. The adsorbents were allowed to dry off $(4 \mathrm{~h})$ to remove any residual liquids from the first cycle of fermentation. The adsorbents were then transferred into $3 \times 350 \mathrm{~mL}$ cooked GM ( $30^{\circ}$ Brix) and incubated at $28^{\circ} \mathrm{C}$ for the duration of the second cycle of fermentations.

\subsection{Evaluation of the Integrity of the Immobilization Matrices}

Before and after the first cycle of fermentations, samples of the matrices were evaluated using a scanning electron microscope (SEM) (Thermo Fisher Nova NanoSEM 230 with a field emission gun (FEG), Eindhoven, Netherlands). Ca-alginate beads were transferred into $1.5 \mathrm{~mL}$ microtubes containing $2.5 \%(v / v)$ glutaraldehyde and kept at $4{ }^{\circ} \mathrm{C}$ for approximately $8 \mathrm{~h}$. Thereafter, the glutaraldehyde was discarded, and the samples underwent a dehydration procedure by submerging the beads in a series of alcohol concentrations, i.e., $30 \%, 40 \%, 50 \%, 60 \%, 70 \%, 90 \%, 95 \%$ to $100 \%(v / v)$ for $5 \mathrm{~min}$ in each alcohol concentration. Subsequently, samples were air-dried for a few hours before SEM analyses. The CC and OWC were allowed to dry for $24 \mathrm{~h}$ before SEM analyses. Ca-alginate beads, CC and OWC were mounted on $10 \mathrm{~mm}$ aluminum pin stubs (Agar Scientific, Essex, United Kingdom) coated with carbon 
glue (Agar Scientific, Chelmsford, Essex, United Kingdom). All samples were sputter-coated with carbon (Agar Scientific, Essex, United Kingdom) using a vacuum evaporator for $90 \mathrm{~s}$. The samples were then scanned under the SEM using several magnifications $(1000 \times 5000 \times$ and $10,000 \times)$ at an acceleration voltage of $20 \mathrm{kV}$. Additionally, the size of beads was measured using a light microscope (Leica Wild M400, Wetzlar, Hesse, Germany) to evaluate bead size reduction.

\subsection{Sensory Evaluation and Statistical Analysis}

At the end of the first cycle fermentations, all cell immobilization matrices were removed from the BSV, subsequent to centrifugation of the vinegar samples to remove debris. Vinegars were kept at ambient temperature $\left(22-24{ }^{\circ} \mathrm{C}\right)$ prior to organoleptic evaluation. The vinegars were evaluated by sixteen trained judges (male (5), female (11), with ages ranging between 20 and 65) from the Agricultural Research Council (South Africa) who were trained using commercial Balsamic Vinegar of Modena (all produced in Italy) and one locally produced wine vinegar. The commercial vinegars were mostly purchased from supermarket chains in Stellenbosch, South Africa. The "Check All That Applies" (CATA) method $[17,18]$ was used to evaluate the vinegars, six per day, over a period of 5 days. Eleven main descriptor categories were evaluated (Appearance-Color, Appearance-Viscosity, Appearance-Clarity, Overall aroma intensity, Aroma and Flavor description, Taste-sweet/acid, Acid-sugar balance, After taste, After taste persistence and Liking rating) with 49 sub-categories for all the main categories. The data was compared to data of 29 commercial balsamic vinegars (identities not disclosed), which were also evaluated by the same panel of judges. The data from the CATA questions were analyzed by correspondence analysis (CA) to produce a bi-dimensional representation (biplot) of the vinegar samples and the relationship between samples and attributes of the CATA questions. The CA was performed using XLSTAT (Version 2015.1.03.15485, Addinsoft, Paris, France). Selected sensory data categories were also analyzed to give a detailed view of specific categories, e.g., the 'liking' rating.

\section{Results and Discussion}

\subsection{Comparative Analyses of Sugar Consumption Rates for First and Second Cycle BSV Fermentations}

The first cycle of the fermentations was successfully completed (Figure 1) with sugar consumption rates similar for all fermentations studied. These results are similar to previous work $[3,4]$. Fermentations carried out using cells adsorbed onto OWC had the highest sugar consumption rates $\left(4.97 \mathrm{~g} \mathrm{~L}^{-1} \mathrm{day}^{-1}\right)$, followed by Ca-alginate beads and CC, resulting in the lowest sugar consumption rates (Figure 1). The second cycle fermentations had notably lower sugar consumption rates, compared to the first fermentation cycle (Figure 1). A decline of sugar consumption when immobilized cells were reused was calculated at relative differences of $94.7 \%, 56.2 \%$ and $31.7 \%$ for CC, OWC and Ca-alginate beads, respectively. Overall, the Ca-alginate beads had the lowest differentiation in sugar consumption rates when cells entrapped in the beads were reused (Figure 1). The results indicated that Ca-alginate beads served a more suitable matrix for the protection of the immobilized consortium, compared to the CC and OWC. In theory, when the entrapment technique is used, cells are encapsulated and are protected from the environment in contrast to the adsorbed cells on CC and OWC. Although the adsorption technique for CC and OWC preparation prevents cells from being freely suspended into the fermentation medium, the cells are still exposed to the fermentation conditions, which in fact can make the cells ineffective in subsequent fermentations. It is important to indicate that the production of TBV, rice vinegar and some wine vinegars also use the back-slopping approach, which is similar to re-using microbial cells in the form of a "seed culture/vinegar". The seed vinegar, often called "mother vinegar", is an undefined starter culture extracted from the previously fermented vinegar for consistency purposes and not to speed up the process of subsequent fermentations $[19,20]$. Although cell immobilization has been described by several researchers as suitable for cell recyclability [11,13-16], the results of this investigation show that cell recyclability is not efficient for BSV production. 


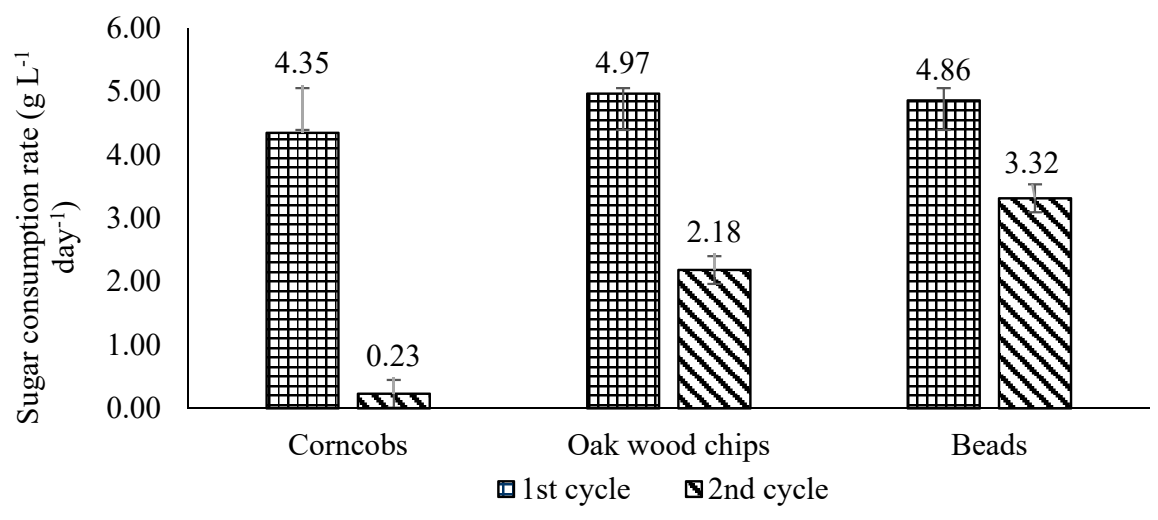

Figure 1. Sugar consumption rates for two cycles of balsamic-styled vinegar (BSV) fermentation using recycled immobilized cells.

\subsection{Comparative Analyses of Acetification Rates for First and Second Cycle BSV Fermentations}

The rate of acetic acid formation is the most important step in the BSV production process since the effectiveness and success of the process are determined by this step. As expected, and in agreement with previous work [3,4], the first cycle of fermentations completed successfully with regard to the acetification rate (Figure 2). Cells entrapped in Ca-alginate beads had the highest acetification rates $\left(2.51 \mathrm{~g} \mathrm{~L}^{-1}\right.$ day $\left.^{-1}\right)$, followed by CC $\left(2.27 \mathrm{~g} \mathrm{~L}^{-1}\right.$ day $\left.{ }^{-1}\right)$ and OWC $\left(1.17 \mathrm{~g} \mathrm{~L}^{-1} \mathrm{day}^{-1}\right)$. However, the acetification rates were slightly reduced, compared to previous studies $[3,4]$. This could be due to the cell immobilization process used in this study, whereby yeasts and bacteria cells were immobilized as a consortium prior to entrapment and absorption on to the selected matrices-a strategy that was different to the previous work [3,4]. Admittedly, biological systems such as fermentations may not always behave similarly due to biological and environmental factors. The second cycle of fermentations had lower acetification rates for all treatments studied, compared to the first cycle (Figure 2). The reductions in acetification rates were calculated at relative differences of $86.8 \%$, $94.0 \%$ and $64.5 \%$ for CC, OWC and Ca-alginate beads, respectively. Ca-alginate beads had the lowest difference in acetification rates, indicating that $\mathrm{Ca}$-alginate beads provided protection to the yeasts and the AAB. Furthermore, several researchers have investigated alginate beads for reusability instead of the adsorption method [11,13-16]. CC were initially anticipated to have high acetification rates when reused because of their structural attributes, in particular, their porosity and rough surface, which was adequate for BSV production when compared to OWC. However, an acetification rate of $0.3 \mathrm{~g} \mathrm{~L}^{-1} \mathrm{day}^{-1}$ for the second cycle fermentations indicate a sluggish fermentation. Hypothetically, the sluggishness was attributed to the use of sterile water to cell immobilization matrices instead of saline or a buffer.

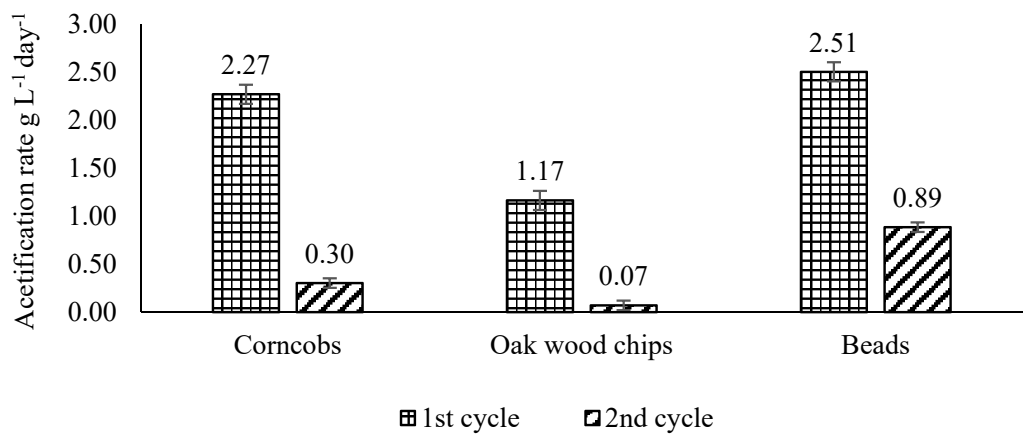

Figure 2. Acetification rates for two cycles of BSV fermentation using recycled immobilized cells. 
The losses and benefits that each cell immobilization matrix offers are crucial. The use of CC for the first cycle of fermentations is beneficial and cheaper than using Ca-alginate beads. Consequently, a producer might have to reconsider repeating the adsorption process to conduct the second batch of fermentations. This would include the development of a preparation strategy for the CC such that its attributes closely resemble those of Ca-alginate beads. Overall, the current study confirmed that the OWC were inefficient in achieving rapid fermentations. In previous work [4], OWC resulted in acetification rates similar to those of free-floating cells, which defeated the aim of decreasing BSV fermentation time by using immobilized cells. However, considerations were given to how OWC might improve the sensorial attributes of the vinegar and were therefore included in this study. OWC had a lower cell affinity, compared to $\mathrm{CC}$ and some of the yeast, and AAB were not adsorbed on the surface after the first batch of fermentations, which is in agreement with previous studies [21].

The acetification rates obtained when using Ca-alginate beads for the second cycle could be acceptable depending on the manufacturer's goals. However, since Ca-alginate is costly (Table 2), it might be advantageous to reuse the beads, although the acetification rates may be reduced by up to $64.5 \%$ and the fermentation period may increase from 19 to 50 days (Table 3), which will further increase operational costs, it would be advisable to reuse the beads to save on inoculum cost in large-scale operations.

Table 2. Cell immobilization matrices used in the study and their sale price.

\begin{tabular}{|c|c|c|}
\hline $\begin{array}{c}\text { Cell Immobilization } \\
\text { Matrix }\end{array}$ & ${ }^{1}$ Price (USD) (\$) per $250 \mathrm{~g}$ & $\begin{array}{l}\text { Quantity of Cell Immobilization Matrices } \\
\text { Used per } 350 \mathrm{~mL} \text { Fermentation Volume }\end{array}$ \\
\hline Calcium alginate & 63.24 & $\begin{array}{c}0.56 \mathrm{~g} \text { per bead } \\
\text { (20 mL of alginate solution infused with cells) }\end{array}$ \\
\hline Oakwood chips & 5.96 & $108.58 \mathrm{~cm}^{2}$ \\
\hline Corncobs & $\begin{array}{c}0.043-0.11 \\
\text { (generally sold in tons } \sim \$ 170.30 \text { to } \$ 454.13 \text { per ton) }\end{array}$ & $117 \mathrm{~cm}^{2}$ \\
\hline
\end{tabular}

${ }^{1}$ USD: United States of America Dollar.

Table 3. Fermentation period for both cycles of fermentation.

\begin{tabular}{ccc}
\hline Cell Immobilization Matrix & First Cycle Fermentation Time (Days) & Second Cycle Fermentation Time (Days) \\
\hline Corncobs & 21 & Sluggish fermentation \\
\hline Oakwood chips & 40 & Sluggish fermentation \\
\hline Ca-alginate beads & 19 & 50 \\
\hline
\end{tabular}

NB: Initial grape must before fermentation had $12.7 \mathrm{~g} \mathrm{~L}^{-1}$ of total acid and fermentations were monitored until a total acidity concentration of $60 \mathrm{~g} \mathrm{~L}^{-1}$ was achieved. Sluggish fermentations are regarded as those fermentations that do not reach $60 \mathrm{~g} \mathrm{~L}^{-1}$ or take an unusually long time to reach $60 \mathrm{~g} \mathrm{~L}^{-1}$ of total acid.

Another reason that could have affected the second cycle of fermentations was the adaptation process of the immobilized cells when the beads were transferred into the second cycle fermentation. Although cell immobilization offers protection for microorganisms in a system such as that of BSV production, the yeast may not survive when the acetic acid concentration reaches $60 \mathrm{~g} \mathrm{~L}^{-1}$. Furthermore, it might also be beneficial to consider reducing the fermentation working volume for the second cycle of fermentations to account for the reduction of cells after the first cycle. Therefore, an alternate approach would be sequential inoculations, i.e., yeast followed by the AAB, rather than co-inoculations. Immobilized yeast cells can be utilized to perform the alcoholic fermentation until the desired alcohol concentration is reached. Thereafter, immobilized AAB cells can be introduced into the system after transferring the yeast to the next batch. This method could retain the activity of both yeast and $A A B$ immobilized cells. Other possible modifications that could be used to improve the reusability of the immobilized cells are the use of other methods of adsorbing the cells on the surface of the selected matrices, such as dynamic batch, reactor loading and electrode positioning processes [21]. 


\subsection{Structural Morphology of Cell Immobilization Matrices before and after BSV Fermentation}

\subsubsection{Ca-Alginate Beads}

The changes in structural morphology of the cell immobilization matrices after fermentation have a major impact on the effectiveness of the matrices when they are reused. With regard to Ca-alginate beads, it was evident that the structure of the beads underwent several alterations during the first cycle of fermentation (Figure 3). Several textures were observed, which varied from rough with bumps, rock texture, smooth with undulated bumps and crusts including some ridge and furrow-like structures. The changes in bead structure were initially discovered by measuring the size of the beads, whereby a $20 \%$ (4.5 to $3.6 \mathrm{~mm}$ ) reduction in bead size was observed. The effects of size reduction of the beads were also observed at a $1000 \times$ magnification (Figure 3B), whereby the surface texture of the beads showed some folds (furrow), in contrast to Figure 3A. The reduction in bead size is possibly due to the loss of moisture and the high acid concentration during BSV fermentation. At a magnification of $5000 \times$, protruding structures were present on the beads before fermentation with pores that were congregated (Figure 3C); however, after fermentation (Figure 3D), the beads appeared to have a smooth surface with undulated bumps and ruptured pores. At 10,000× magnification (Figure 3E,F), a rock-like surface was observed on the beads before fermentation, while the beads after fermentation had a smooth surface with an undulated crust after fermentation. The changes in the bead structure and size affected the performance of the beads' immobilized consortia during the second cycle of fermentations. The loss of structural integrity of the beads possibly led to the reduction in cell retention and thus lowered productivity rates. Rao et al. [14] discovered that increasing the alginate concentration during the preparation of the beads reduces the loss of structural integrity and the loss of cells. A low alginate concentration was attributed to large pore sizes and thus a high release of cells into the fermentation medium during fermentation. Consequently, increasing the alginate concentrations and exploring other methods that could increase the robustness of the beads are crucial for BSV fermentations.

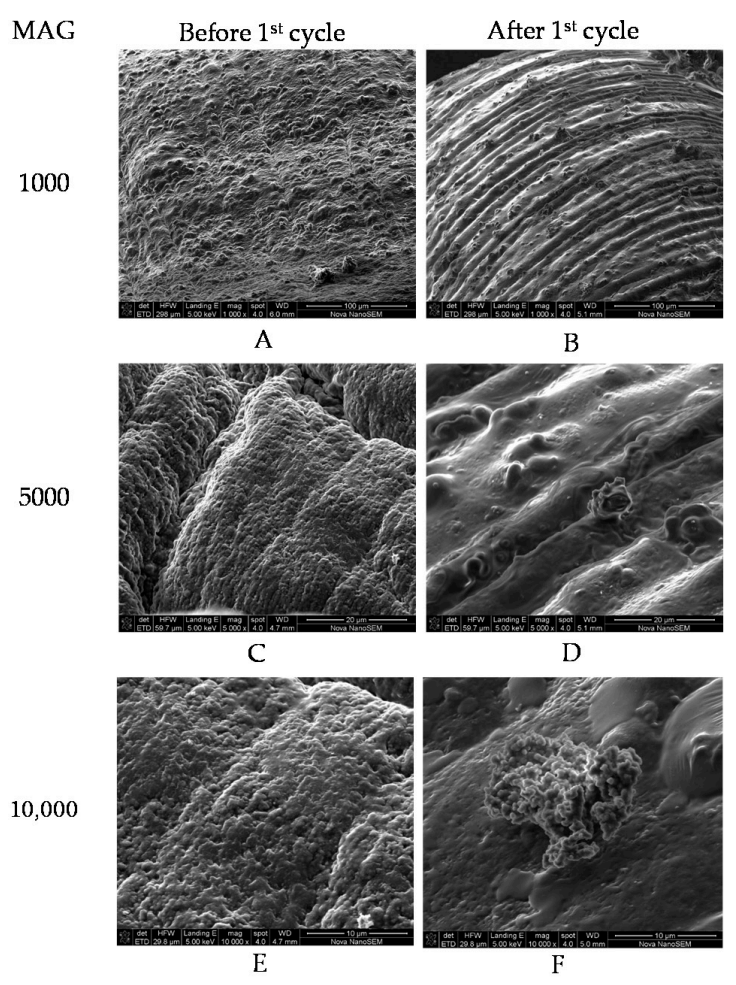

Figure 3. Scanning electron micrographs (SEM) of Ca-alginate beads before and after first cycle fermentations at $1000 \times(\mathbf{A}, \mathbf{B}), 5000 \times(\mathbf{C}, \mathbf{D})$ and $10,000 \times(\mathbf{E}, \mathbf{F})$ magnifications. 


\subsubsection{Oakwood Chips}

It was found that OWC had a similar appearance before and after the first cycle of fermentations (Figure 4), which was attributed to their robust nature. At a magnification of 1000x, typical plant material and wood-like surface were evident (Figure 4A,B). Furthermore, microbial cells were visible in both images, while at a magnification of 5000 $\times$, the OWC were still similar in appearance before and after the first cycle of fermentations (Figure 4C,D). Furthermore, unevenly arranged microbial cells that resemble yeast were present on the surface of the OWC. Although OWC did not result in high acetification rates, sugar consumption was still observed for both fermentation cycles (Figure 1), which substantiates the yeast observed (Figure 4C,D). This meant that the yeast could have a higher cell adsorption capacity to the wood surface compared to AAB.

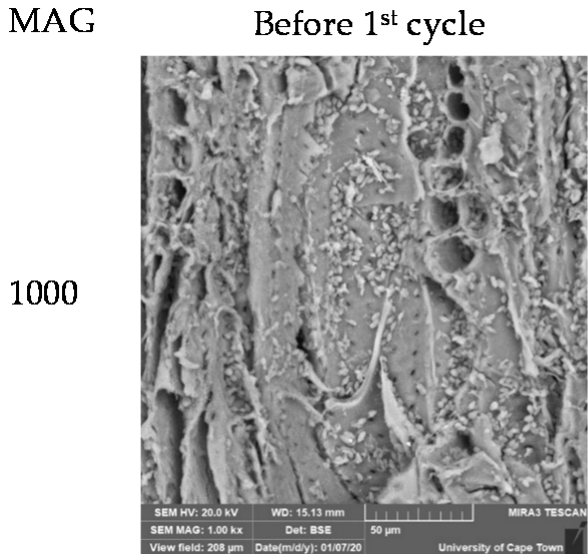

A

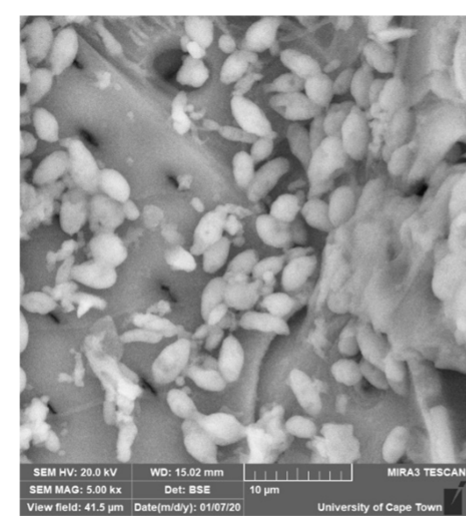

C

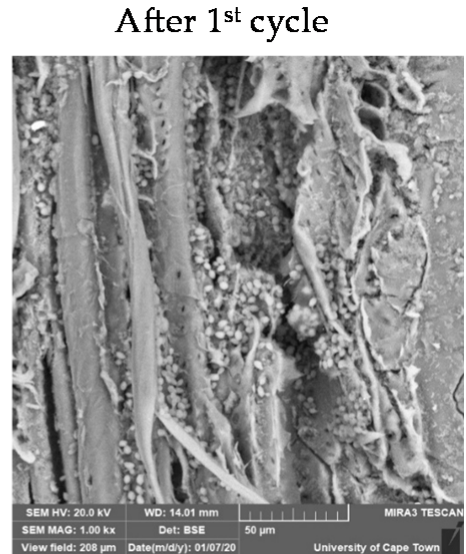

B

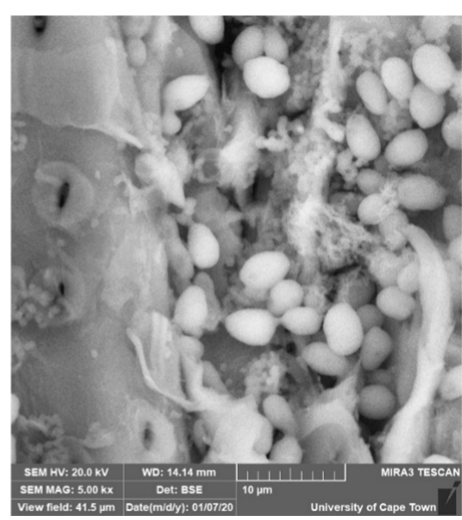

$\mathrm{D}$

Figure 4. Scanning electron micrographs of oak wood chips before and after first cycle fermentations at $1000 \times(\mathbf{A}, \mathbf{B})$ and $5000 \times(\mathbf{C}, \mathbf{D})$ magnifications.

\subsubsection{Corncobs}

Corncobs generally have a rough and porous surface. The SEM images provided a microscopic representation of the level of roughness and porosity of the CC (Figure 5). At a magnification of 1000x, an analysis of the chaff/bee's wing portion of the CC showed that after the first cycle of fermentation (Figure 6B), the $\mathrm{CC}$ had larger pores, compared to the pores before the first cycle (Figure 6A). The increase in pore size could be attributed to the high acid concentrations $\left(60 \mathrm{~g} \mathrm{~L}^{-1}\right)$, which might have led to the surface alterations. Furthermore, an increased quantity of microbial cells was noted after the first cycle of fermentation (Figure 6B,D,F). However, the SEM images do not show the viability of the cells; therefore, the increase in cells can be correlated to growth during the first cycle, with most of the cells being non-viable when transferred into the second cycle. 


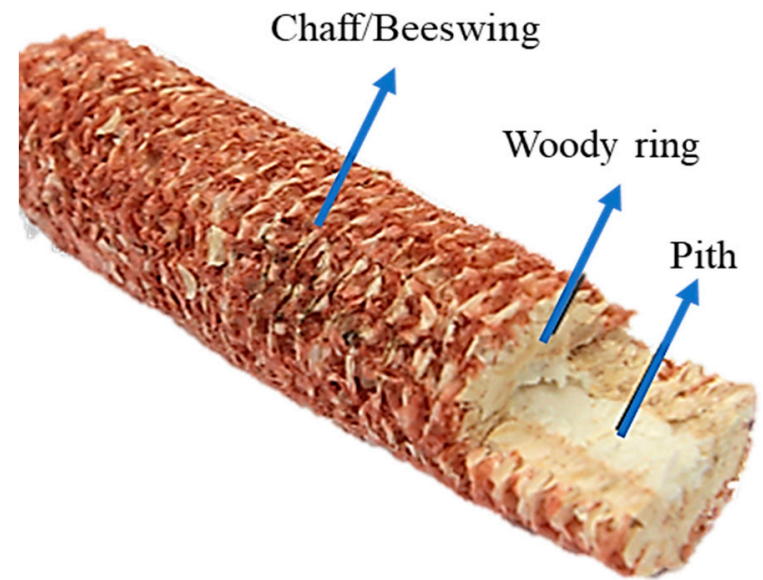

Figure 5. An image showing the structure of a corncob. Image adapted from Anonymous [22].

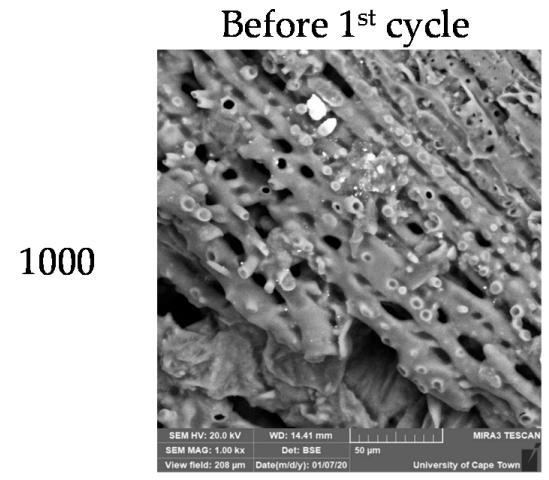

A

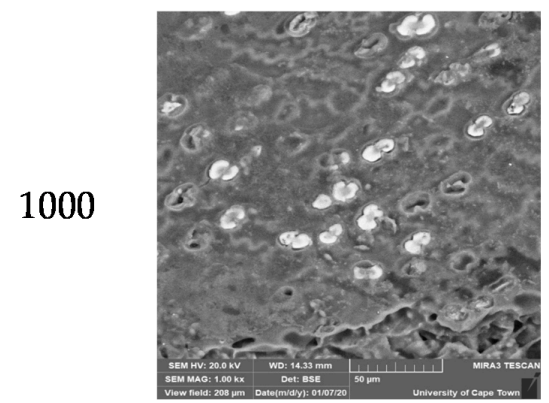

C

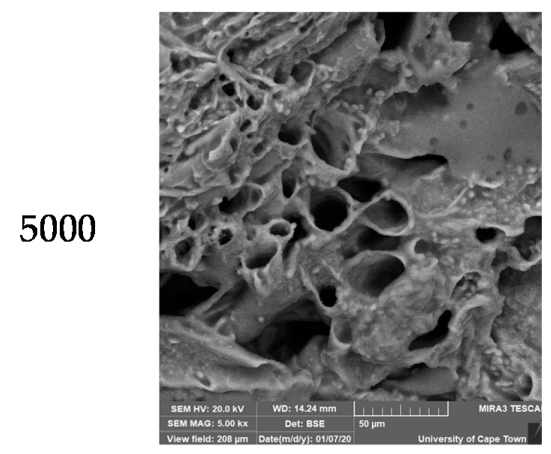

E

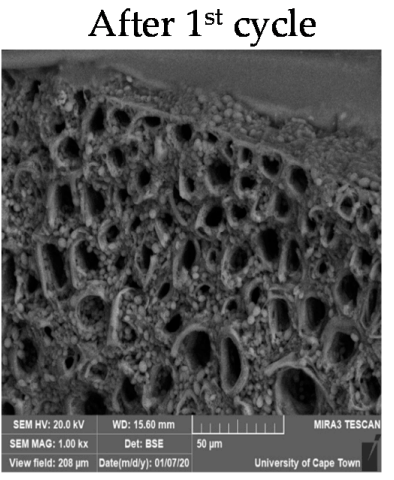

B

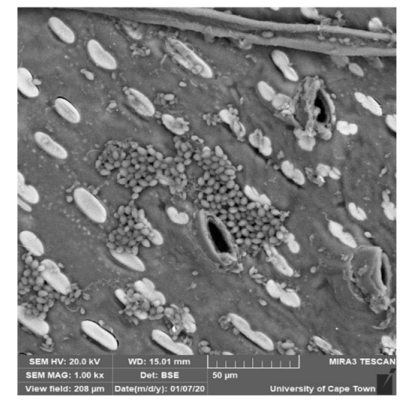

D

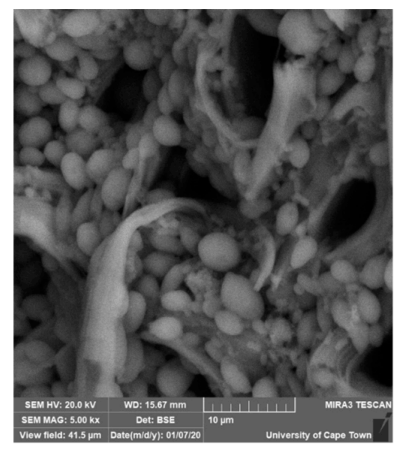

F

Figure 6. Scanning electron micrographs of corncobs before and after first cycle fermentations at $1000 \times(\mathbf{A}-\mathbf{D})$ and $5000 \times(\mathbf{E}, \mathbf{F})$ magnifications. 
The analysis of the pith and woody ring section (Figure 5) of the CC showed capsule-like structures, which resemble bacteria (Figure 6D). The capsule-like structures were higher in quantity and more prominent after the first cycle of fermentations (Figure 6D), compared to pre-fermentation (Figure 6C). If the capsule-like structures are bacterial cells, that means that the pith and wood ring section of the CC has a higher cell affinity for AAB cell adsorption than the chaff/bee's wing portion. At a magnification of $1000 \times$, the analyses of the chaff/bee's wing portion (Figure 5) of the CC further showed a higher quantity of microbial cells (predominantly yeasts cells) around the pores/layers of the bee's wing after the first cycle of fermentation (Figure 6F), compared to pre-fermentation (Figure 6E). Overall, all the SEM images referred to demonstrated that during BSV fermentation, the microbial cells multiplied on the surface of CC. The SEM images also proved that CC (Figure 6F) has a higher cell affinity than OWC (Figure 4D), i.e., CC appeared to have a substantially higher number of microbial cells, compared to OWC. Furthermore, the reduction of productivity rate on the second cycle of fermentations could be attributed to the loss of viability of cells and not to the loss of cells on the immobilization matrix.

\subsection{Sensory Attributes of Balsamic-Styled Vinegar Versus Commercial Balsamic Vinegar}

Only the first cycle fermentations reached the expected total acidity concentration for BSV; therefore, only the first cycle products were evaluated for sensorial characteristics. The yeast consortium was selected based on the ability to produce acid, pleasant aroma, their osmophilic characteristics and percentage alcohol production under pre-determined conditions (data not published). The cell immobilization matrices were selected based on the knowledge that they are environmentally friendly and do not have any harmful effects on humans when present in food products. The two matrices used are different with regard to biological and physical composition, which makes it possible for the matrices to contribute positively or negatively to the sensorial attributes of the BSV by transmitting favorable or unfavorable compounds. Generally, the sensorial qualities of any food product determine the success of the product, research and development, including the production process to be designed. Ideally, the general appearance of acceptable BSV is described as dense and viscous, resembling the texture of syrup, while being glossy and having a deep brown color. A balsamic vinegar should not be as harsh on the nose and palate as spirit vinegars. Another attribute is a balance between sweetness and acidity [23].

In this study, a comparative analysis was conducted between BSV and data of 29 commercial balsamic vinegars obtained from South African supermarkets. A wine vinegar was also added as an external reference. The visual appearance of the BSV (Figure 7A) was described as light brown with low viscosity, similar to that of wine vinegar, while the majority of the commercial balsamic vinegars were described as dark brown or brown-black, with medium viscosity. These observations were expected because the BSV was evaluated directly post-fermentation with no maturation, and no addition of caramel or thickening agents, as in the case of TBV of Modena. With regard to flavor (Figure 7B), all the BSV's were judged to have a flavor of cooked fruit and some saltiness, slightly sweet and less intense. The commercial balsamic vinegars were described as having diverse attributes, as shown on the correspondence analyses (CA) plot (Figure 7B).

Most of the commercial balsamic vinegars were described as balanced with only a few being described as unbalanced and highly acidic. The BSV's were described as slightly acidic for the CC and OWC treatments, while BSV's fermented with Ca-alginate beads were described as unbalanced and too acidic (Figure 7C). The reason for these descriptions is unclear because all the BSV products had similar acid concentrations. However, it is possible that this could be due to low residual sugar content in the Ca-alginate beads products, which caused the products to be perceived as highly acidic.

The consumer acceptance or "liking rating" is an important rating because it determines if the product has the potential for commercial production. The BSV's from the CC and Ca-alginate beads treatments were associated with 'liked a lot', while the BSV's obtained from the OWC treatments were 'neither liked' nor 'disliked'. Contrary to the above, most of the commercial balsamic vinegars were rated 
across the likeness rating spectrum, i.e., from 'dislike' to 'like a lot'. The data, therefore, demonstrate that the BSV's can potentially be commercialized after some refinements and improvements are done.
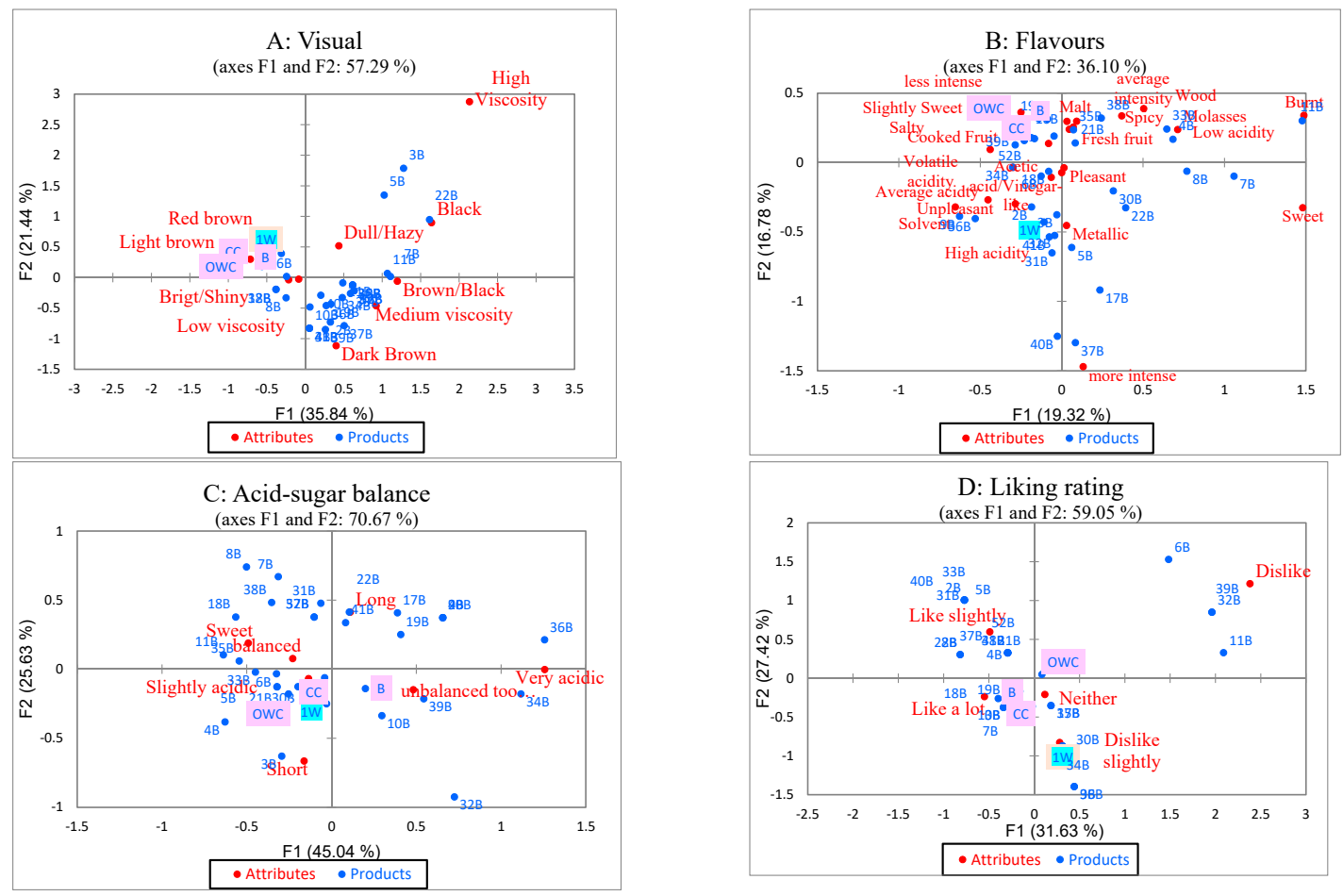

Figure 7. Correspondence analysis of CATA (check all that apply) sensory data for three BSV and 29 commercial balsamic vinegars (blue). (A) Visual, (B) Flavors, (C) Acid-sugar balance, (D) Consumer acceptance/liking rating. All BSV samples were shaded purple (CC: corncobs, OWC: oakwood chips, B: beads), with one wine vinegar being shaded light blue (1W: wine vinegar).

\section{Conclusions and Recommendations}

Chemical and sensory data showed that CC and Ca-alginate beads are suitable immobilization matrices with regard to acetification rates and sensorial attributes for the first cycle of fermentations. The reusability of immobilized cells for BSV production led to slower acetification rates on the second cycle of fermentations, compared to the first cycle. Cells immobilized using Ca-alginate beads resulted in higher acetification rates for the second cycle, compared to cells adsorbed on both $\mathrm{CC}$ and OWC. Therefore, for sustainable and good-quality BSV production, it is recommended that a fresh inoculum should be used for successive cycles. SEM analyses showed that Ca-alginate beads undergo visible structural alterations after the first cycle of fermentations, while CC and OWC did not show structural modifications due to their robustness. The data generated from this study can allow large-scale BSV producers to make informed decisions when choosing the immobilization matrix and technique to optimize production rates, organoleptic attributes and cell reusability, while minimizing operational costs. Methods to improve the robustness of alginate beads and the use of sequential inoculation strategies are recommended for further testing of the cell immobilization techniques. Investigating suitable methods for quantifying immobilized biomass changes throughout a BSV fermentation with the current support materials is also recommended.

Author Contributions: Conceptualization, U.F.H. and N.P.J.; methodology, U.F.H., B.S.C., N.P.J., M.M.-N., and H.W.d.P.; formal analysis, U.F.H., M.M.-N., N.P.J., B.S.C., H.W.d.P., and S.K.O.N.; investigation, U.F.H., N.P.J., and M.M.-N.; resources, N.P.J., H.W.d.P., and S.K.O.N.; data curation, U.F.H., N.P.J., M.B., B.S.C., H.W.d.P., and S.K.O.N.; writing - original draft preparation, U.F.H.; review and editing, U.F.H., N.P.J., B.S.C., H.W.d.P., M.M.-N., and S.K.O.N.; supervision, N.P.J., H.W.d.P., and S.K.O.N.; funding acquisition, N.P.J. and S.K.O.N. All authors have read and agreed to the published version of the manuscript. 
Funding: Financial support was provided by the Department of Agriculture Forestry and Fisheries (DAFF project (21.1.1/18/PRS-01/NVR), Agricultural Research Council (ARC) and the Cape Peninsula University of Technology (grant number RK 16 and RK 45) (South Africa).

Acknowledgments: The authors would like to acknowledge the Agricultural Research Council and the Bioresource Engineering Research Group (BioERG), Department of Biotechnology, Cape Peninsula University of Technology, for funding and infrastructure.

Conflicts of Interest: The authors hereby declare that they have no conflict of interest.

\section{References}

1. Tesfaye, W.; Morales, M.L.; Garcia-Parrilla, M.C.; Troncoso, A.M. Wine vinegar: Technology, authenticity and quality evaluation. Trends Food Sci. Technol. 2002, 13, 12-21. [CrossRef]

2. Fernández-Pérez, R.; Torres, C.; Sanz, S.; Ruiz-Larrea, F. Strain typing of acetic acid bacteria responsible for vinegar production by the submerged elaboration method. Food Microbiol. 2010, 27, 973-978. [CrossRef] [PubMed]

3. Hutchinson, U.F.; Ntwampe, S.K.O.; Ngongang, M.M.; Du Plessis, H.W.; Chidi, B.S.; Saulse, C.K.L.N.; Jolly, N.P. Cell immobilization by Gel entrapment in Ca-alginate beads for balsamic-styled vinegar production. In Proceedings of the 10th International Conference on Advances in Science, Engineering, Technology and Healthcare (ASETH-18), Cape Town, South Africa, 19-20 November 2018.

4. Hutchinson, U.F.; Gqozo, S.; Jolly, N.P.; Chidi, B.S.; Du Plessis, H.W.; Mewa-Ngongang, M.; Ntwampe, S.K. Aeration, agitation and cell immobilization on corncobs and oak wood chips effects on balsamic-styled vinegar production. Foods 2019, 8, 303. [CrossRef] [PubMed]

5. Vaughan, T.; Seo, C.W.; Marshall, W.E. Removal of selected metal ions from aqueous solution using modified corncobs. Bioresour. Technol. 2001, 78, 133-139. [CrossRef]

6. Sun, Y.; Cheng, J. Hydrolysis of lignocellulosic materials for ethanol production: A review. Bioresour. Technol. 2002, 83, 1-11. [CrossRef]

7. Shen, Y.; Zhang, Y.; Ma, T.; Bao, X.; Du, F.; Zhuang, G.; Qu, Y. Simultaneous saccharification and fermentation of acid-pretreated corncobs with a recombinant Saccharomyces cerevisiae expressing $\beta$-glucosidase. Bioresour. Technol. 2008, 99, 5099-5103. [CrossRef] [PubMed]

8. Kyraleou, M.; Kallithraka, S.; Chira, K.; Tzanakouli, E.; Ligas, I.; Kotseridis, Y. Differentiation of wines treated with wood chips based on their phenolic content, volatile composition, and sensory parameters. J. Food Sci. 2015, 80, C2701-C2710. [CrossRef] [PubMed]

9. Laqui-Estaña, J.; López-Solís, R.; Peña-Neira, Á.; Medel-Marabolí, M.; Obreque-Slier, E. Wines in contact with oak wood: The impact of the variety (Carménère and Cabernet Sauvignon), format (barrels, chips and staves), and aging time on the phenolic composition. J. Sci. Food Agric. 2019, 99, 436-448. [CrossRef] [PubMed]

10. Hecht, H.; Srebnik, S. Structural characterization of sodium alginate and calcium alginate. Biomacromolecules 2016, 17, 2160-2167. [CrossRef] [PubMed]

11. Park, J.K.; Jin, Y.B.; Chang, H.N. Reusable biosorbents in capsules from Zoogloea ramigera cells for cadmium removal. Biotechnol. Bioeng. 1999, 63, 116-121. [CrossRef]

12. Kocher, G.S.; Kalra, K.L.; Phutela, R.P. Comparative production of sugarcane vinegar by different immobilization techniques. J. Inst. Brew. 2006, 112, 264-266. [CrossRef]

13. Rahman, R.N.Z.A.; Ghazali, F.M.; Salleh, A.B.; Basri, M. Biodegradation of hydrocarbon contamination by immobilized bacterial cells. J. Microbiol. 2006, 44, 354-359. [PubMed]

14. Rao, C.S.; Madhavendra, S.S.; Rao, R.S.; Hobbs, P.J.; Prakasham, R.S. Studies on improving the immobilized bead reusability and alkaline protease production by isolated immobilized Bacillus circulans (MTCC 6811) using overall evaluation criteria. Appl. Biochem. Biotechnol. 2008, 150, 65-83.

15. Nigam, V.K.; Khandelwal, A.K.; Gothwal, R.K.; Mohan, M.K.; Choudhury, B.; Vidyarthi, A.S.; Ghosh, P. Nitrilase-catalysed conversion of acrylonitrile by free and immobilized cells of Streptomyces sp. J. Biosci. 2009, 34, 21-26. [CrossRef] [PubMed]

16. Shyamkumar, R.; Moorthy, I.M.G.; Ponmurugan, K.; Baskar, R. Production of L-glutamic acid with Corynebacterium glutamicum (NCIM 2168) and Pseudomonas reptilivora (NCIM 2598): A study on immobilization and reusability. Avicenna J. Med Biotechnol. 2014, 6, 163. [PubMed] 
17. Adams, J.; Williams, A.; Lancaster, B.; Foley, M. Advantages and uses of check-all-that-apply response compared to traditional scaling of attributes for salty snacks. In Proceedings of the 7th Pangborn Sensory Science Symposium, Minneapolis, MN, USA, 12-16 August 2007; Volume 16.

18. Pramudya, R.C.; Seo, H.S. Using Check-All-That-Apply (CATA) method for determining product temperature-dependent sensory-attribute variations: A case study of cooked rice. Food Res. Int. 2018, 105, 724-732. [CrossRef] [PubMed]

19. Gullo, M.; Giudici, P. Acetic acid bacteria in traditional balsamic vinegar: Phenotypic traits relevant for starter cultures selection. Int. J. Food Microbiol. 2008, 125, 46-53. [CrossRef] [PubMed]

20. Bekatorou, A. Current Industrial Vinegar Production. In Advances in Vinegar Production; CRC press Taylor \& Francis group: New York, NY, USA, 2019; Volume 1, p. 83.

21. Hutchinson, U.F.; Jolly, N.P.; Chidi, B.S.; Ngongang, M.M.; Ntwampe, S.K.O. Vinegar Engineering: A Bioprocess Perspective. Food Eng. Rev. 2019, 11, 290-305. [CrossRef]

22. Anonymous. The Andersons Cob Products. Available online: https://andersonscob.com/about-theandersons-cob-products/slide_bkgd2/ (accessed on 18 January 2020).

23. Giudici, P.; Gullo, M.; Solieri, L.; Falcone, P.M. Technological and microbiological aspects of traditional balsamic vinegar and their influence on quality and sensorial properties. Adv. Food Nutr. Res. 2009, 58, 137-182. [PubMed]

Publisher's Note: MDPI stays neutral with regard to jurisdictional claims in published maps and institutional affiliations. 